\title{
Resilient reinstatement: what can we learn from the 2007 flooding in England?
}

\author{
R. Joseph ${ }^{1,2}$, D. Proverbs ${ }^{1} \&$ J. Lamond ${ }^{1}$ \\ ${ }^{I}$ Faculty of Environment and Technology, \\ University of the West of England, UK \\ ${ }^{2}$ Cunningham Lindsey, UK
}

\begin{abstract}
In the face of increased flooding in the UK, it is becoming increasingly important to understand the ways in which flood experience can affect homeowners' attitude towards taking precautionary measures to protect their homes. This could include investing in flood adaptation measures to reduce likely flood damage and hence exposure to flood risk. This research sought to investigate, the level of awareness, implementation and the costs of resilience measures, from those homeowners who had experienced flood damage to their properties in 2007 summer flooding in England. A questionnaire survey was thus employed to elicit the extent to which flood experience influenced the decision to adopt flood resilient measures during reinstatement works. The findings revealed that some $82 \%$ of houses inundated were returned to their pre-incident condition i.e. with no improved resilience to future flooding. It was found that the level of awareness of resilience measures among the respondents was high; however, the level of implementation was quite low. Only $10 \%$ of those who indicated that they invested resilience measure actually implemented a full package of the measures. This shows that more needs to be done by flood risk management stakeholders to encourage full uptake of resilience measures. Loss adjusters and surveyors are better placed to advice homeowners of the potential risk reduction measures, which can be implemented during reinstatement period. Further, there is a need for policy development in the form of revising the current Building Regulations for refurbishing or reinstating flood damaged buildings in order to encourage the up-take of resilient reinstatement.
\end{abstract}

Keywords: flood adaptation, flood damage, flood experience, resilience measures. 


\section{Introduction}

The cost of flood damage in the UK has risen significantly since 1998 [1]. Currently, in the UK, over 5.2 million properties and 2.4 million people are at risk of flooding, and annual average damages are estimated to be more than $£ 1$ billion [2]. However, climate change and the increasing urbanisation of our societies are increasing flood risk $[2,3]$. In particular, there now appears to be clear evidence that climate change will lead to an increase in the frequency and severity of extreme precipitation and other weather events [4]; for the UK, this may well result in wetter and stormier winters [5]. As such, The "Foresight Future Flooding" report raises the prospect of a 4-10-fold increase in coastal flood risk by the $2080 \mathrm{~s}$ as a result of sea level rise alone [2]. The UK Government policy on flood management can be summed up by the strategy of "Making space for Water" which combines the provision and maintenance of engineered flood defences with the recognition that flooding can never be prevented entirely [6].

The direct financial damages related to the flooding of residential properties can be significant. Depending on flood depth, duration of flooding and property types, it is estimated that the cost of flooding can range from $£ 15,000$ to over $£ 80,000$ for a single residential property and its contents [7]. The impact of flooding at an individual household level can also result in less direct, insurance-related impacts [8,9], with premiums and flood-related excesses potentially increasing following a flood event and as a result of making insurance claims $[10,11]$.

Whilst large scale flood defences can be effective in reducing widespread flood risk, such developments are costly, both in terms of time and financial resources. Consequently, cost benefit analysis does not always yield a favourable result for large scale defence schemes, and the extensive flooding that has recently occurred within the UK has strengthened calls for greater use of adaptation measures $[12,13]$. In the UK, such measures are generally classified as resistance (measures to keep water out of properties) or resilience measures (installed to reduce the damaged impact of flooding on the fabric of building) [14]. Keeping water out is a natural desire of property owners but, it is not always possible or cost effective to prevent flooding of property, especially when the anticipated flood depth is up to $1000 \mathrm{~mm}$. Resilience measures are often preferred, allowing water into the property in the knowledge that preparations have been taken to minimise the damage caused. These adaptation measures are designed to achieve two important objectives: to limit the financial impact on the flood victim or their insurer by reducing damage to contents and building fabric and to reduce the time used to reinstate properties, thereby, allowing communities to return to normality quickly in the aftermath of the flood event. Research has shown that implementing adaptation measures during flood recovery period can effectively reduce the cost of the measures [15].

Review of extant literature revealed that the uptake of resilience measures in residential properties remains persistently low [15], with one study finding that only $16 \%$ of households and $32 \%$ of small-medium enterprises (SMEs) in areas 
of significant flood risk have taken practical steps to reduce their exposure to the potential flood risk [16]. Common reasons for the low uptake of the measures include underestimation of flood risk, a lack of understanding about flood protection responsibilities and concerns over the costs and aesthetics of such measures $[17,18]$.

This study explores, the level of awareness, implementation and the costs of resilient reinstatement after 2007 summer flooding in England. Those homeowners who had experienced flood damage to their properties were the focus of the study. The 2007 summer flood event provides an interesting case study as it was reported to be widespread, and the cost of reinstatement work during the recovery process was the highest insurers had ever paid (prior to 2007) in England on a single flood event. Adapting existing properties to potential future flood risk can be achieved by investing either in resistance or resilience measures, or the combination of the two measures. The focus of this study is on resilience measures. The concept of resilient reinstatement and specifications, which can be incorporated during the flood reinstatement process and the costs of resilient reinstatement are discussed in this paper. The concluding part of the paper outlines some of the lessons learned from the level of awareness, implementation and the actual cost spent by those homeowners who implemented one form of resilience measures as a result of reinstatement work to their properties following the 2007 summer flood event.

\section{Concept of resilient reinstatement}

Flood water can enter buildings swiftly, causing pervasive damage to floors, walls, finishes and services, and in more severe floods the flood water can cause structural damage $[16,19]$. The vulnerability of buildings depends on the construction methods and building materials used in its construction. The processes and pathways by which water enters a building during a flood depends on the characteristics of the flood, specifically flood depth and duration, and water velocity [20]. Nevertheless, for floods deeper than $1000 \mathrm{~mm}$, it is recommended that no attempt should be made to keep the water out of the house, because the build up of water pressure could cause external walls to become unstable, leading to serious structural damage [20]. It has been suggested that if a property is vulnerable to repeated flooding, it is important to limit damage to speed up drying/re-occupation by making the inside of the property more resilient to floodwater.

\subsection{Flood resilient measures/specifications}

Due to the additional cost involved in implementing resilience measures, they are generally recommended for buildings with exceptionally high risk of flooding. Materials such as water-resistant paints and coatings, for example, can prevent floodwater soaking into the external face of the walls. Other materials such as lime-based plaster, as opposed to gypsum plaster have good water-resilient properties and dry out quickly. Solid concrete floors can also 
prevent water seeping into the fabric of a building. Other measures include refitting electrical sockets and electricity meter boxes above the anticipated flood levels. Despite the extra cost of these measures, it has been suggested that the implementation of resilient measures will reduce the repair costs in the long-term assuming repeat flooding [16]. Table 1, shows the most widely used and recognised resilience measures/specifications.

Table 1: List of resilience specifications.

\begin{tabular}{|l|}
\hline \multicolumn{1}{|c|}{ Resilience measures } \\
\hline Replace timber floors with concrete and cover with tiles. \\
\hline Replace carpet with ceramic tiles. \\
\hline $\begin{array}{l}\text { Replace chipboard/MDF kitchen and bathroom units with plastic equivalents or } \\
\text { stainless steel. }\end{array}$ \\
\hline $\begin{array}{l}\text { Replace gypsum plaster with more water-resistant material, such as lime plaster or } \\
\text { cement sand render. }\end{array}$ \\
\hline Apply water resistant paint to walls. \\
\hline Move service meters, boiler, and electrical points well above likely flood level. \\
\hline $\begin{array}{l}\text { Replace softwood timber skirting with plastic or hardwood and apply water resilience } \\
\text { paint. }\end{array}$ \\
\hline Replace softwood door and window frames with water resilient alternative. \\
\hline Replace mineral insulation with cell insulation. \\
\hline
\end{tabular}

Source: Joseph [7].

The effectiveness of such resilient measures is dependent on the expected volume and duration of the flood water and it has been established that in some cases these measures are not always cost effective [16, 19], therefore proper flood risk assessment should be carried out before investing in resilient reinstatement. Conversely, there are resilience measures for buildings that are inexpensive, especially if implemented during other building works [19] or may be cost neutral, for example setting electrical sockets further up the wall where the electricity supply is dropped down from the ceiling [14].

\subsection{Cost of resilient reinstatement}

Previous research carried out on behalf of the ABI [15], revealed that, on average, resilient reinstatement costs over $40 \%(£ 12,000)$ more than traditional reinstatement. It was stressed that there are significant variations around this $40 \%$ average, both between house types (i.e. bungalow, block of flats, terraced, semi-detached and detached houses) and within house types. Although, the authors further reiterate that resilient reinstatement could costs as little as $15 \%$ or as much as $70 \%$ more than traditional reinstatement [15]. The reasons for the wide variation were; property owners' individual preferences and different approaches to reinstatement methods adopted by different surveyors, despite the available guidance such as Proverbs and Soetanto [21]; Garvin et al. [22] and PAS 64 [23]. Some resilient measures can be introduced on a cost neutral basis, and therefore not all aspects of resilient reinstatement measures increase the cost 
of reinstatement. According to the economic modelling study which was conducted on behalf of Department for Environment, Food and Rural Affairs (DEFRA) and Environment Agency (EA) resilience measures are most cost effective when conducted as part of a programme of resilient repair following a flood [16].

Table 2 shows the additional cost of resilience measures, these costs are the extra over cost incurred during reinstatement of flood damaged building to make those properties flood resilience against future flooding. The cost ranges from as low as $£ 12,000$ for a terraced house flooded to a depth of $150 \mathrm{~mm}$ and as high as $£ 28,300$ for a bungalow flooded to a depth of $1000 \mathrm{~mm}$. The additional cost of resilience measures presented in Table 2 was based on resilience specifications presented in Table 1. Understandably, as the depth of the floodwater increases, so does the cost of resilience measures, therefore, accuracy of expected future flood depth is important when estimating the cost of resilience measures. Getting this wrong may invalidate the resilience measures which were taken, thereby leading to waste of money already spent on implementing resilience measures.

Table 2: $\quad$ Costs of resistance and resilience measures for different building types, flood depths and deployment methods.

\begin{tabular}{|l|l|l|l|l|l|}
\hline \multirow{2}{*}{ Building Types } & \multicolumn{5}{|c|}{ Cost of resilience measures $\left(\mathbf{C M}_{\mathbf{r t}}\right)$ in flood depth (mm) } \\
& \multicolumn{5}{|c|}{ categories } \\
\cline { 2 - 6 } & $\mathbf{0}-\mathbf{1 5 0}$ & $\mathbf{1 5 1 - 3 0 0}$ & $\mathbf{3 0 1}-\mathbf{5 0 0}$ & $\mathbf{5 0 1 - 1 0 0 0}$ & $>\mathbf{1 0 0 0}$ \\
\hline Bungalow & $£ 15,200$ & $£ 16,200$ & $£ 20,395$ & $£ 28,300$ & \\
\hline Detached & $£ 13,300$ & $£ 14,600$ & $£ 16,700$ & $£ 23,700$ & $£ 24,800$ \\
\hline Semi-detached & $£ 12,500$ & $£ 13,600$ & $£ 15,800$ & $£ 15,000$ & $£ 22,600$ \\
\hline Terraced & $£ 12,000$ & $£ 15,300$ & $£ 16,800$ & $£ 15,400$ & $£ 20,200$ \\
\hline
\end{tabular}

Source: Joseph [7].

\section{Research methodology}

An extensive survey was undertaken among those homeowners, who experienced flood damage to their properties in the summer 2007 flood event, in order to gain a better understanding of their flood experiences; to investigate their understanding of resilience reinstatement; and to examine their responsiveness to resilient reinstatement while their properties were being repaired. This contributed to the evidence base needed to inform the effective promotion of resilient reinstatement during flood recovery period. The investigation took the form of postal questionnaire surveys. The mix of the targeted population, which comprises of young and elderly people, dictates the postal approach instead of online method of questionnaire distribution. The summer 2007 flood event in England was selected as the focus of the study. This flood event was widespread and it affected much of the UK during June and July 2007 which followed the wettest-ever May since national records began in 1766 [12]. The survey was carried out in 2013 some 6 years after the event and was designed to gather information in two key areas; 
1. Flood experience (previous and subsequent flood experiences).

2. Level of awareness and implementation of resilience measures.

Prior to distributing the questionnaire to the main respondents, a pilot survey was conducted among homeowners who were not part of the main survey to determine the suitability of the questionnaire format and the contents, before being distributed to the targeted population. The feedback received from the pilot survey showed that the questions were easy to understand, therefore, it was decided that the main questionnaire survey could proceed. Figure 1, shows the survey location, which comprises of cities in the North and South of England. The survey locations were selected from amongst the locations flooded during the 2007 flood event. The selection criteria was based on the need to represent the widest possible variation both geographical and flood typology while retaining minimum numbers of properties within each selected site. To that end only sites with greater than 50 affected properties were included in the survey. In total, 2309 questionnaires were distributed via post to homeowners. The survey yielded 280 responses, representing a response rate of $12.1 \%$, which is considered a reasonable return for an unsolicited postal survey.

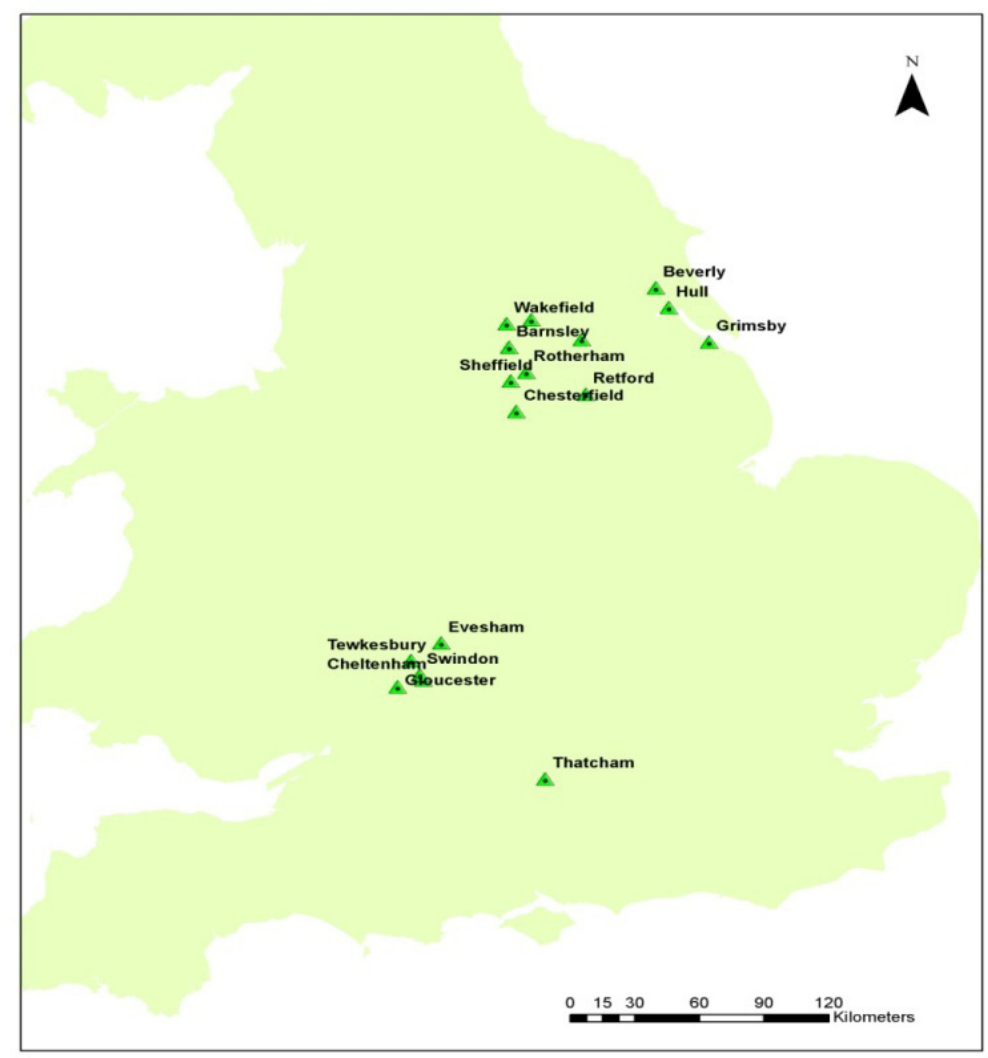

Figure 1: Survey site locations. 


\section{Research results}

Detailed analysis of the dataset was carried out and is presented in this section. Respondents were asked if they had experienced flood damage to their properties before and after 2007. Most respondents (77\%) had no previous flood experience prior to the 2007 flood event; $16 \%$ reported that they had experienced one previous damaging flood to their properties prior to the 2007 event; and approximately $4 \%$ had been flooded twice and $3 \%$ had been flooded more than twice. This information is important because it is anticipated that those respondents who had been flooded more than once, are more likely to invest in resilience measures. Research has shown that experience of flooding can be a source of motivation to individuals to undertake precautionary measures against future flooding [24]. Further, respondents were asked if they had experienced further flood damage to their properties following the 2007 flood event. Some $91 \%$ of respondents did not experience a flood event after the 2007 summer flood event. This means that only $9 \%$ of respondents had experienced further flooding after 2007.

\subsection{Level of awareness of resilience measures}

Figure 2 illustrates the analysis of the level of awareness of different types of resilience measures, which homeowners can implement during flood recovery period. The result shows that, the level of awareness ranges from $11 \%$ to $61 \%$. Some $61 \%$ of respondents are aware of replacing floor carpet with tiles as one form of resilience measure. In total, $60 \%$ of respondents are aware of replacing suspended timber floor with concrete floor as one form of resilience measure. Over half of the respondents (51\%) are aware of raising electrical socket above the anticipated flood level, as one form of resilience measures. These results differ from earlier UK studies, which suggest a lower level of awareness of resilience measures [14]. Majority of respondents were unaware of replacing mineral insulation with cell insulation $(89 \%)$ and using plastic $(85 \%)$ or stainless steel (81\%) kitchen units instead of MDF boards as form of resilience measures.

The low level of awareness of these measures can be linked to the fact that, these measures are not readily available. The use of stainless kitchen units is synonymous to commercial kitchens, and the plastic kitchen units are not currently readily available in the building construction market. It can be inferred from these results, that, the majority of the respondents are aware of the most commonly used resilient measures.

\subsection{Level of implementation of resilience measures}

Despite the relatively high number of respondents being aware of (at least) one form of resilience measure to protect their property, the results presented in Figure 3, show that fewer people actually used the opportunity of the 2007 flood 


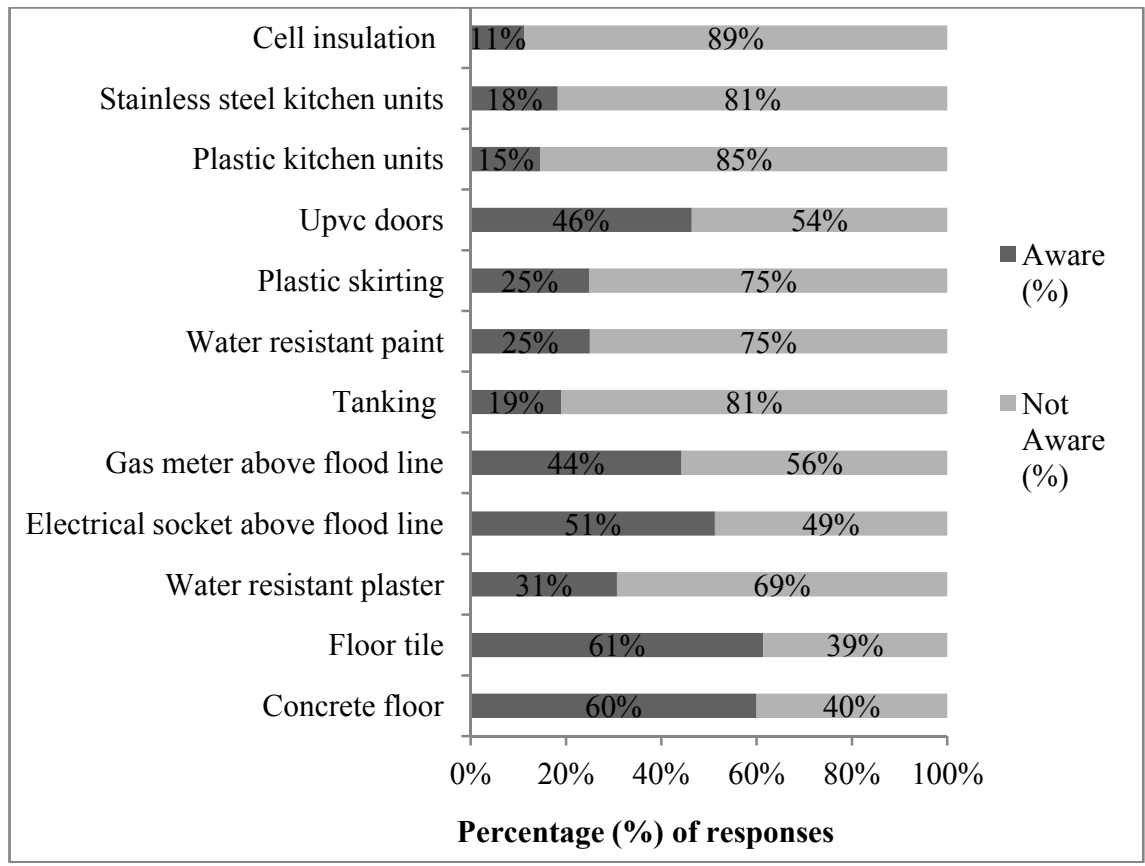

Figure 2: Percentages of respondents who are 'aware and not aware' of resilience measures.

event to invest in resilience measures. Among those who were aware of resilience measure of using plastic or hardwood skirting board instead of softwood timber skirting, 23\% actually invested in plastic or hardwood skirting. The relatively high percentage of people who invested in this resilience measures can be linked to the fact that, the cost increase from softwood skirting to plastic skirting is very low [15]. In some cases, the cost may be incorporated in the total cost of reinstatement, which means the insurer may have paid for it unknowingly. Some $14 \%$ and $18 \%$ of respondents decided to raise gas and electric meters and electrical sockets above the anticipated flood levels respectively. These resilience measures are normally cost neutral, if implemented during the reinstatement process.

The fact that not all respondents who indicated that they were aware of these forms of resilience measures actually implemented the measures shows that, apart from awareness, there are other barriers, such as aesthetic considerations and emotional attachment to the existing layout of fittings and features this accords with previous study [18], that barrier to uptake of resilience reinstatement is not only hinges on financial constraints. 


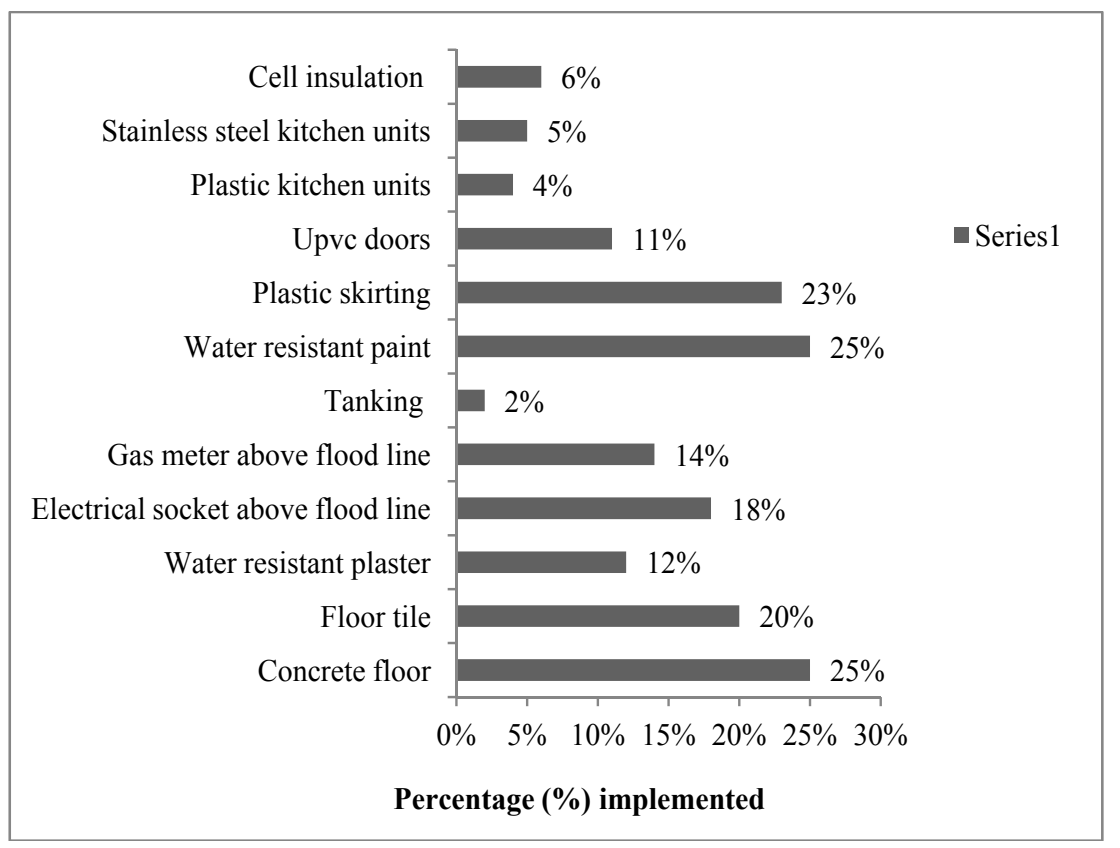

Figure 3: Distribution of respondents who had implemented one form of resilience measures.

\subsection{Analysis of costs invested by respondents in resilience measures}

Research has shown that implementing resilience measures during flood reinstatement process is less expensive, because the contractor's site set up cost would have been paid by the insurer as part of the normal insurance reinstatement work. Thus, the homeowner would only be required to pay the extra cost of resilience measures, for instance, when a suspended timber floor is to be replaced with concrete floor, the insurer would paid for the cost of replacing the timber floor including the cost of preliminaries, however, the homeowner would be required to pay the difference between the cost of timber and concrete floors, excluding any preliminaries costs.

Analysis of the cost invested by those respondents who implemented at least one form of resilience measure was carried out. The total amount homeowners invested in resilience measures during the flood reinstatement process ranged from $£ 1000$ to $£ 45,000$. With $49 \%$ of respondents investing up to $£ 1000$ (equivalent to extra over cost of replacing softwood skirting board with plastic or hardwood). $16 \%$ of those who implemented resilience measures, invested up to $£ 3000$, whilst only $2 \%$ invested up to $£ 45,000$.

The overall median, which homeowners invested in resilience measures, was $£ 1,500$. This figure is lower when compared to the earlier research such as $[13,15,16]$, which suggest a higher value of $£ 12,000$ minimum for full package of resilience measure. This indicates that among those respondents who had 
implemented resilience measures, full package of resilience measures were not implemented. $10 \%$ of those who invested in the measures actually implemented full package of the resilience measure, such as replacing timber floor with concrete, raising electrical socket and gas meters above the anticipated flood level.

\section{Discussion and conclusions}

The aim of governments to place more of the responsibility for flood management onto the floodplain population requires the floodplain population to take action to reduce the impact of flooding on their properties. Resilience measures have a place in the hierarchy of flood risk management solutions for existing properties. However, they are generally regarded as the last resort for locations and situations where no other measure, such as large scale flood defences, can be provided. The findings reported herein are part of a research into the development of a comprehensive costs and benefits of property level flood risk adaptation measures in England. In addition to broadly confirming the findings of earlier studies into the level of awareness and take-up of resilience measures, the findings from this research have shed some light onto some of the key issues surrounding the uptake of resilience measure, especially among those that have been flooded before. Five (5) key lessons revolving round the level of awareness and implementation of resilience measures were learned from the output of this research, these are summarised at the end of this section, under the heading 'key lessons learned'.

The emergence of effective public awareness and engagement campaigns by organisations such as Environment Agency; Department for Environment, Food and Rural Affairs (DEFRA); National Flood Forum (NFF); and Association of British Insurers (ABI) seem to have led to an increase in awareness of resilience measures, amongst the respondents. However, the fact that majority of the respondents are aware of one form of resilience measures, did not result in increase uptake of the measures. This research shows that some $82 \%$ of properties did not adopt any form of resilient reinstatement. Of those who did implement resilience measures in the reinstatement process, a vast majority $(90 \%)$ failed to implement a full range of resilient measures. The reasons why partial resilience measures were taken by those people were generally unknown. Further research to investigate this is therefore recommended.

For effective flood risk management strategies, understanding the reasons why some homeowners did not take up resilience reinstatement during flood recovery period in 2007 is important, as this is a key step in developing strategies to increase the uptake of resilience measures. In order to embrace the principle of resilience reinstatement, loss adjusters and surveyors, often the link between the insurer and homeowners are better placed to advise their clients (homeowners and insurers) of the potential risk reduction measures, which can be implemented during reinstatement period, most especially, those measures that are cost neutral if implemented during reinstatement period. 
The last resort is that, if the level of uptake of resilience reinstatement after flood event continues to be as low as what was revealed in this study, it is recommended that, Government needs to revise the current Building Regulations for refurbishing or reinstating flood damaged buildings in order to force the up-take of resilient reinstatement after flood event.

\section{Key Lessons Learned:}

$>$ The level of awareness of resilience measures among the respondents is relatively higher than reported in previous research.

$>$ Despite the high level of awareness, a majority of respondents did not invest in resilience measures while their properties were being repaired in 2007.

$>$ Among those respondents who invested in the measures, only $1.8 \%$ of the whole sample can be said to have implemented a full package of resilience measures.

$>$ By not implementing a full package of resilience measures, the full benefits of resilience measures cannot be achieved.

$>$ There is still a need to encourage the implementation of resilience measures during flood recovery period, perhaps, by updating the current Building Regulations to force the implementation of resilience measures.

\section{References}

[1] Association of British Insurers. Summer floods 2007: Learning the lessons. London. Association of British Insurers. London, 2007.

[2] Evans, E. P., Ashley, R., Hall, J., Penning-Rowsell, E., Sayers, P., Thorne, C. R. \& Watkinson, A. Foresight. Future Flooding. 1 and 2 London, 2004.

[3] Office of Science and Technology Climate Change Science. Postnote No. 295. Parliamentary Office of Science and Technology, London, 2007.

[4] IPCC Managing the risks of extreme events and disasters to advance climate change adaptation. A special report of working groups I and II of the intergovernmental panel on climate change. Cambridge University Press, Cambridge, 2012.

[5] UKCIP. UK Climate Projections. UK Climate Impacts Programme, DEFRA. http://www.defra.gov.uk/publications/files/pb13274-uk-climateprojections-090617.pdf, 2009.

[6] Rooke, D. The summer of storm. Water and Environment Magazine, (10), pp. 8-9, 2007.

[7] Joseph, R. Development of a comprehensive quantification of the costs and benefits of property level flood risk adaptation measures in England. PhD Thesis. University of the West of England, Bristol, 2014.

[8] Ball T., Geddes A., Werritty A., Black A. \& Easton A. Flood insurance provision and affordability beyond the statement of principles: implication for Scotland. CREW, University of Dundee, 2012. 
[9] Association of British Insurers. Revised Statement of Principles on the Provision of Flood Insurance. ABI, London, 2008.

[10] Association of British Insurers. Under-pricing of the flood element of home insurance for domestic customers at significant flood risk. ABI, London, 2011a.

[11] O’Neill M. \& O’Neill J. Social Justice and the Future of Flood Insurance. Joseph Rowntree Foundation, 2012.

[12] Pitt, M. The Pitt review - Learning lessons from the 2007 floods. H.M. Government Cabinet Office, 2008.

[13] Joseph, R., Proverbs, D., Lamond, J. \& Wassell, P. An analysis of the costs of resilient reinstatement of flood affected properties: A case study of the 2009 flood event in Cockermouth. Structural Survey, 9(4), pp. 279-293, 2011.

[14] DEFRA. Consultation on policy options for promoting property-level flood protection and resilience. DEFRA Report, London, 2008.

[15] Wassell, P., Ayton-Robinson, R., Robinson, D., Joseph, R., Hack, K., Butler, D., Salkeld, I. \& Twomey, J. Resilient Reinstatement: The costs of flood resilient reinstatement of domestic properties. Association of British Insurers, 2009.

[16] Thurston, N., Finlinson, B., Breakspear, R., Williams, N., Shaw, J. \& Chatterton, J. Developing the Evidence Base for Flood Resistance and Resilience. Joint DEFRA/EA Flood and Coastal Erosion Risk Management R\&D. DEFRA. London, 2008.

[17] Werritty A., Houston D., Ball T., Tavendale A. \& Black A. Exploring the social impacts of flood risk and flooding in Scotland. Report to the Scottish Executive, 2007.

[18] Proverbs, D. \& Lamond, J. The barriers to resilient reinstatement of flood damaged homes. Proceedings of 4th International i-Rec ConferenceBuilding Resilience: Achieving Effective Post-disaster Reconstruction. Christchurch, New Zealand, 2008.

[19] Lamond, J.E. \& Proverbs, D.G. Resilience to Flooding: Lessons from International Comparison. Urban Design and Planning, 162(2), pp. 63-70, 2009.

[20] Samwinga, V., Proverbs, D. \& Homan, J. Exploring the Experience of UK Homeowners in Flood Disasters. International Construction Research Conference. Royal Institute of Chartered Surveyors, 2004.

[21] Proverbs, D. \& Soetanto, R. Flood Damaged Property: A guide to repair. Blackwell, Oxford, 2004.

[22] Garvin, S., Reid, J. \& Scott, M. Standards for the Repair of Buildings following Flooding. CIRIA: London, 2005.

[23] PAS 64. Mitigation and Recovery of Water Damaged Buildings - Code of Practice. London: British Standard Institution, 2013.

[24] Kreibich H., Seifert I., Thieken, A. H., Lindquist E., Wagner K. \& Merz B. Recent changes in flood preparedness of private households and businesses in Germany. Regional Environmental Change 11, 59-71, 2011. 